\title{
PENINGKATAN TARAF PEREKONOMIAN MASYARAKAT DESA PENGADANGAN BARAT, KECAMATAN PRINGGASELA, KEBUPATEN LOMBOK TIMUR MELALUI PEMANFAATAN BUAH NANAS MENJADI PRODUK OLAHAN DODOL NANAS
}

\author{
Alvin Naufal Indisa1, Arin Nafiana2, Dwi Armitika Aprilianti3, Ikrar Ali Mursyid4, \\ I. Wayan Sudiarta5, Tuti Apriani3
}

${ }_{1}$ Program Studi Informatika Fakultas Teknik Universitas Mataram

2 Program Studi Bahasa dan Sastra Indonesia Fakultas Keguruan dan IImu Pendidikan Universitas Mataram ${ }_{3}$ Program Studi Pendidikan Pancasila dan Kewarganegaraan Fakultas Keguruan dan IImu Pendidikan Universitas Mataram

4 Program Studi Manajemen Fakultas Ekonomi dan Bisnis Universitas Mataram 5 Program Studi Fisika Fakultas Matematika dan IImu Pengetahuan Alam Universitas Mataram

\begin{abstract}
ABSTRAK. Desa Pengadangan Barat terletak di Kecamatan Pringgasela, Kabupaten Lombok Timur, Provinsi Nusa Tenggara Barat. Banyak potensi yang bisa dikembangkan di desa tersebut, salah satunya pemanfaatan hasil pertanian yakni buah nanas yang melimpah ketika musimnya tiba. Potensi tersebut harus dimanfaatkan agar dapat memberikan manfaat bagi masyarakat Desa Pengadangan Barat dengan cara menghasilkan produk-produk olahan dari buah nanas untuk dapat meningkatkan nilai jual buah tersebut. Salah satu olahan yang dapat dibuat dari buah nanas adalah DONAS (Dodol Nanas). Untuk mewujudkan hal tersebut serangkaian kegiatan dilakukan mulai dari proses pelatihan pembuatan produk, pengemasan, hingga pemasaran. Melalui produk DONAS (Dodol Nanas) diharapkan mampu meningkatkan produktivitas dan memberikan sumber pendapatan baru untuk meningkatkan taraf perekonomian masyarakat Desa Pengadangan Barat.
\end{abstract}

\begin{abstract}
Kata Kunci: Desa Pengadangan Barat, Ekonomi, DONAS (Dodol Nanas)
ABSTRACT. West Pengadangan Village is one of villages which is in Pringgasela District, East Lombok Regency, West Nusa Tenggara Province. There is a lot of potential that can be developed in the village, one of which is the use of agricultural products, which is abundant pineapple when the season arrives. This potential must be utilized in order to be able to provide benefits to the people of West Pengadangan Village by producing processed products from pineapple to increase the selling value of the fruit. One of the preparations that can be made from pineapple is DONAS (Pineapple Dodol). To realize this, a series of activities were carried out starting from the training process of product manufacturing, packaging, to marketing. Through DONAS (Pineapple Dodol) products, it is expected to be able to increase productivity and provide a new source of income to improve the economy of the people of West Pengadangan Village.
\end{abstract}

Keyword: West Pangadangan Village, Economics, DONAS (Pineapple Dodol)

\section{PENDAHULUAN}

Desa Pengadangan Barat, Kecamatan Pringgasela, Kabupaten Lombok Timur, Provinsi Nusa Tenggara Barat memiliki luas wilayah kurang lebih $613 \mathrm{ha} / \mathrm{m} 2$ yang digunakan sebagai pemukiman warga dan digunakan sebagai lahan pertanian, sisanya untuk membangun sarana dan prasarana. 
Pemukiman warga di Desa Pengadangan Barat tersebar ke 10 dusun, terdiri atas Dusun Ketembong, Dusun Dasan Tiga, Dusun Tibu Petung, Dusun Repok Barat, Dusun Sukatain, Dusun Panggungan, Dusun Alon, Dusun Aik Telir, Dusun Pengkelep, dan Dusun Sigek.

Melihat potensi yang ada di Desa Pengadangan Barat dengan banyaknya ketersediaan buah nanas serta ketersediaan bahan pembuatan produk olahan, alat yang dibutuhkan, dan tenaga kerja, kelompok Kuliah Kerja Nyata mengajukan beberapa program kerja untuk membantu mengatasi permasalahan tersebut. Program yang diajukan disusun dengan mempertimbangkan faktor-faktor yang mendukung pengolahan setelah melalui observasi dan wawancara dengan aparat setempat.

Diharapkan melalui program yang dusulkan dapat menambah keterampilan masyarakat untuk mengolah buah nanas yang melimpah pada masa-masa panen. Dengan dilakukannya pengolahan terhadap buah nanas, diharapkan dapat meningkatkan nilai tambah buah nanas tersebut sehingga dapat meningkatkan taraf perekonomian masyarakat.

\section{ANALISIS PERMASALAHAN}

Desa Pengadangan Barat memiliki sumber daya alam yang berlimpah termasuk hasil pertanian berupa buah-buahan. Apalagi buah-buahan Indonesia mempunyai nilai eksotik tinggi, baik dalam bentuk, rasa, maupun aroma. Selain dapat dikonsumsi secara langsung, hasil pertanian ini ternyata juga bisa dikembangkan dan diolah menjadi makanan yang enak dan lezat. Masyarakat belum memanfaatkan aneka buah di lingkungan sekitar secara maksimal. Padahal, olahan dari buah banyak digemari masyarakat. Dengan demikian, tidak menutup kemungkinan olahannya dijadikan peluang usaha yang menjanjikan.

Sering terjadi ketika masa panen tiba, pasokan buah-buahan tersedia dalam jumlah yang berlebihan sehingga menurunkan harga jual. Hal seperti ini dialami pula oleh para petani di Desa Pengadangan Barat. Desa tersebut sebagai penghasil buah nanas yang banyak membuat para petani harus rela memberikan sekarung nanas yang hanya dihargai Rp20.000,00 hingga Rp30.000,00. Tentu hal ini sangat merugikan. Untuk mengatasi hal tersebut, pengolahan buah nanas menjadi panganan sangat membantu petani dalam memanfaatkan hasil pertanian mereka sehingga hasil panen beroleh keuntungan.

\section{SOLUSI YANG DITAWARKAN}

\section{Sosialisasi Program Kerja}

Sosialisasi Program Kerja merupakan kegiatan yang perlu dilakukan setiap pelaksanaan program pengabdian masyarakat. Tujuan dilakukan sosialisasi yakni untuk menginformasikan kepada masyarakat mengenai program-program kerja yang akan dilaksanakan di Desa Pengadangan Barat. Dalam pelaksanaan sosiasialisasi, masyarakat akan diberikan penjelasan mengenai program utama maupun program tambahan mulai dari tujuan dibuatnya program tersebut sampai manfaat yang akan diperoleh masyarakat. Program utama pada pelaksanaan pengabdian masyarakat di Desa Pengadangan Barat yaitu pengolahan buah nanas menjadi DONAS (Dodol Nanas).

\section{Praktik Pembuatan Olahan Dodol Nanas}

Program kerja utama yang diusung oleh mahasiswa KKN Tematik Universitas Mataram di Desa Pengadangan Barat adalah pengolahan buah nanas menjadi DONAS (Dodol Nanas). Sebagaimana diketahui bahwa olahan dari buah banyak digemari masyarakat salah satunya olahan dodol. Dodol nanas merupakan sebuah produk yang berbahan dasar buah nanas yang diolah oleh masyarakat Pengadangan Barat. Praktik pembuatan dodol nanas diawali dengan menunjukkan 
bahan-bahan dan alat-alat yang dibutuhkan dalam pembuatan produk. Ada enam langkah yang akan dilakukan dalam pembuatan olahan dodol nanas dilanjutkan dengan pengemasan sehingga produk olahan tampil menarik lalu diberikan penjelasan mengenai cara pemasaran produk yang siap dijual.

\section{HASIL DAN PEMBAHASAN}

Pelaksanaan pengabdian kepada masyarakat tentang peningkatan taraf perekonomian masyarakat Desa Pengadangan Barat, Kecamatan Pringgasela, Kebupaten Lombok Timur melalui pemanfaatan buah nanas menjadi produk olahan DONAS (Dodol Nanas) berjalan sesuai rencana. Hal ini terlihat dari antusiasme masyarakat ketika mengikuti sosialisasi program kerja dan praktik pembuatan produk olahan dodol nanas yang difasilitasi oleh tim pengabdian masyarakat Universitas Mataram.

\section{Sosialiasi Program Kerja}

Sosialisasi dilaksanakan pada tanggal 2 Januari 2020 di Kantor Desa Pengadangan Barat. Acara tersebut dihadiri oleh Kepala Desa, staf desa, ibu-ibu kader, ibu-ibu PKK, Kepala dusun, serta seluruh mahasiswa Kuliah Kerja Nyata (KKN) Universitas Mataram. Dalam pelaksanaan sosialisasi, ketua KKN Temati Universitas Mataram tahun 2019/2020 melakukan presentasi terkait program kerja yang akan dilaksanakan selama 45 hari di Desa Pengadangan Barat. Program utama pelaksanaan pengabdian masyarakat di Desa Pengadangan Barat yaitu pelatihan pembuatan produk olahan DONAS (Dodol Nanas) disertai cara penmgemasan dan pemasaran produk olahan.

Sumber dana untuk acara ini berasal dari mahasiswa yang ditujukan untuk konsumsi dan penyediaan perlengkapan lainnya. Adapun hambatan yang ditemui pada saat melaksanakan acara ini yaitu pada saat pengumpulan warga dalam acara sosialisasi cukup sulit mengingat sebagian besar warga adalah petani sehingga pada saat acara diadakannya warga sedang pergi bertani dan berkebun. Sebagai solusinya kami mengundang masyarakat dengan mendatangi rumahnya. Dengan bergitu, sosialisasi dapat berjalan dengan lancar sesuai yang diharapkan.

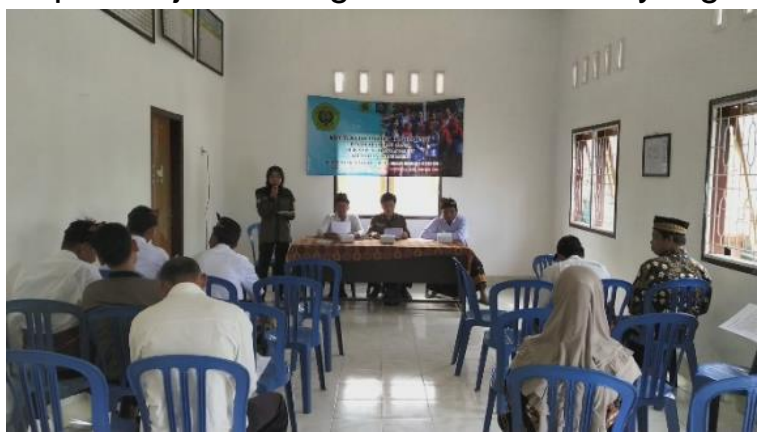

Gambar 1. Sosialisasi DONAS

\section{Praktik Pembuatan Olahan Dodol Nanas}

Program kerja utama yang diusung oleh mahasiswa KKN Tematik Universitas Mataram di Desa Pengadangan Barat adalah Pengolahan Buah Nanas menjadi DONAS (Dodol Nanas). Dodol nanas merupakan sebuah produk yang berbahan dasar buah nanas yang diolah oleh masyarakat Pengadangan Barat. Pembuatan Donas ini dilakasanakan di tiga tempat, yakni Dusun Aik Telir pada hari Jumat tanggal 10 Januari 2020, Dusun Repok Barat pada hari Rabu tanggal 15 Januari 2020, dan Dusun Dasan Tiga pada hari Rabu tanggal 22 Januari 2020. 


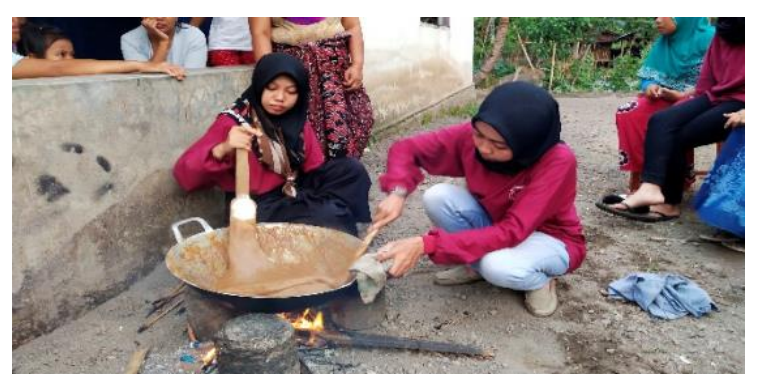

Gambar 2. Pelatihan DONAS Di Dasan Tiga

Pelatihan pembuatan dodol nanas ini dilaksanakan dengan mengajak masyarakat yang ada di dusun tersebut dan juga mengundang beberapa staf desa dan ibu-ibu kader serta ibu-ibu PKK untuk berpartisipasi dalam kegiatan ini. Pelaksanaan pembuatan dodol nanas ini berjalan dengan lancar di setiap dusunnya dan semua masyarakat yang ikut berpartisipasi sangat antusias dalam membuat dodol nanas. Tidak ada kendala yang dihadapi saat pembuatan dodol nanas di setiap dusun di Desa Pengadangan Barat. Berikut bahan, alat, serta langkah-langkah pembuatan dodol nanas.

\section{Pembuatan Dodol Nanas}

Proses pembuatan dimulai dengan mempersiapkan alat dan bahan. Hal ini dilakukan guna mengantisipasi kendala teknis yang bisa terjadi apabila baha dan alat tiak dipersiapkan dengan matang. Adapu bahan yang harus disiapkan yaitu: (1) Nanas; (2) Beras Ketan; (3) Gula Merah; (4) GulaPasir; (5) Sari Buah Nanas; (6) Santan Kelapa; \& (7) Agar-Agar Putih

Persiapan kedua yaitu menyiapkan alat. Adapun alat yang diperlukan yaitu : (1) Wajan; (2) Saringan; (3) Spatula; (4) Baskom; (5) Parutan Kelapa; \& (6) Pengkocok Adonan.

Setelah alat dan bahan tersedia, dilakukan beberapa prosedur kerja dalam mengolah nanas menjadi produk olahan dodol nanas. Adapun Langkah-langkah Pembuatan Dodol Nanas yaitu: (1) persiapkan alat dan bahan; (2) Kupas nanas kemudian parut.; (3) Tepung ketan disangrai kurang lebih selama 5 menit; (4) Santan kelapa dipanaskan sambil diaduk rata hingga mendidih, lalu masukkan gula merah dan gula pasir secukupnya, kemudian tuang agar-agar hingga semua bahanbahan tersebut tercampur rata; (5) Setelah itu, tepung dan santan dicampur hingga merata lalu tambahkan parutan nanas dan sari buah nanas; terakhir (6) Selanjutnya adonan nanas dimasukkan ke dalam wajan sambil diaduk secara terus menerus hingga dodol berwarna kecoklatan dan tidak lengket saat dikemas.

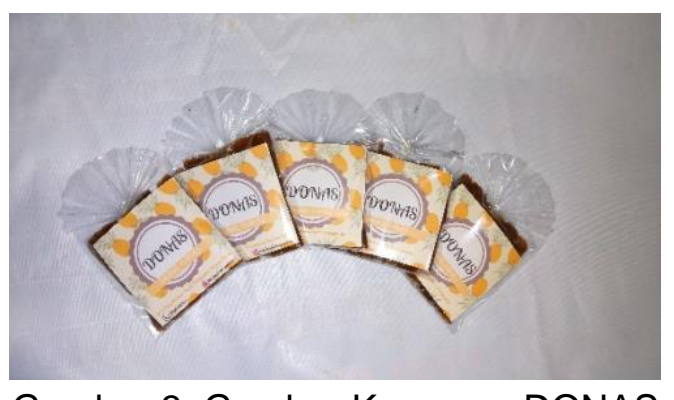

Gambar 3. Gambar Kemasan DONAS

Pengemasan dan promosi produk olahan merupakan program tambahan yang kami usungkan untuk desa Pengadangan Barat. Program kerja tambahan ini kami satukan dengan program kerja utama yakni produk olahan, karena waktu pelaksanaan program kerja tambahan ini sama dengan waktu pelaksanaan program kerja utama. Adanya program ini guna bertujuan untuk menunjang program utama yakni pengolahan buah nanas menjadi dodol nanas. Dengan adanya 
program tambahan pengemasan pada produk olahan ini, masyarakat diharapkan mampu untuk melakukan pengemasan terhadap dodol nanas dengan kreativitas yang dimiliki oleh masyarakat setempat, sehingga produk yang akan dipasarkan dapat terlihat menarik dimata pembelinya. Promosi untuk produk olahan dapat dilakukan secara langsung (offline) maupun secara tidak langsung (online) di media sosial. Secara langsung (offline) artinya masyarakat dapat memasarkan produk olahan ini ke pasar atau ke toko-toko. Promosi secara online dapat dilakukan di media sosial yakni di Facebook atau WhatsApp, sehingga dapat memudahkan masyarakat dalam mejajakan produk olahan yang telah dibuat.

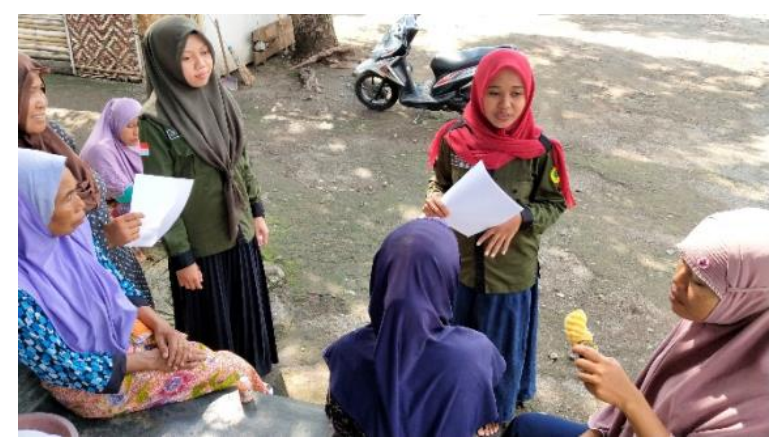

Gambar 4. Promosi ke Ibu-lbu Repok Barat

\section{KESIMPULAN}

Pelaksanaan pengabdian kepada masyarakat tentang Peningkatan Taraf Perekonomian Masyarakat Desa Pengadangan Barat Kecamatan Pringgasela Kebupaten Lombok Timur Melalui Pemanfaatan Buah Nanas Menjadi Produk Olahan Dodol Nanas berjalan sesuai rencana. Hal ini terlihat dari antusiasme masyarakat ketika mengikuti sosialisasi program kerja dan praktik pembuatan produk olahan dodol nanas.

Masyarakat terutama ibu-ibu rumah tangga mengetahui proses pembuatan produk olahan dodol nanas disertai pengemasan dan pemasaran produk tersebut. Nanas yang harganya murah ketika musimnya tiba dapat diolah menjadi produk oalahan yang banyak digemari masyarakat sehingga harga jual buah nanas meningkat. Dengan demikian, taraf perekonomian masyarakat di Desa Pengadagan Barat dapat ditingkatkan melalui pemanfaatan buah nanas menjadi olahan DONAS (Dodol Nanas).

\section{UCAPAN TERIMA KASIH}

Tim Pengabdian kepada Masyarakat mengucapkan terima kasih kepada Universitas Mataram yang telah menyelenggarakan program Kuliah Kerja Nyata (KKN) bagi setiap mahasiswa. Ucapan terima kasih juga kami sampaikan kepada pihak-pihak yang terlibat, yaitu Kepala Desa Pengadangan Barat beserta jajarannya, Bapak I Wayan Sudiarta, Ph.D., selaku Dosen Pembimbing Lapangan (DPL), serta semua peserta yang hadir sehingga kegiatan pengabdian ini dapat terselenggara dengan baik.

\section{REFERENSI}

Badan Penelitian dan Pengembangan Pertanian. 2012. Aneka Olahan Buah dan Sayur. IAARD PRESS: Jakarta. 
Badan Pusat Statistik Provinsi Nusa Tenggara Barat. 2017. Statistik Produksi Tanaman Hortikultura Provinsi Nusa Tenggara Barat 2017. BPS NTB.

BPS. 2018. NTB dalam Angka. Badan Pusat Statistik Provinsi Nusa Tenggara Barat.

Murniati, Endyah. 2012. Sang Nanas Bersisik Manis di Lidah. Surabaya Intellectual Club: Surabaya.

Profil Desa Pengadangan Barat, Kecamatan Pringgasela, Kabupaten Lombok Timur. Tahun 2017.

Satuhu S, Sunarmani. 2004. Membuat Aneka Dodol Buah. Penebar Swadaya: Jakarta. 